\title{
PG13 Packaging Cells Produce Recombinant Retroviruses Carrying a Diphtheria Toxin Mutant Which Kills Cancer Cells
}

\author{
Jian Qiao and Manuel Caruso* \\ Le Centre de Recherche en Cancérologie de l'Université Laval, L'Hôtel Dieu de Québec, Centre Hospitalier Universitaire de \\ Québec, Québec G1R 2J6, Canada
}

Received 1 February 2002/Accepted 2 April 2002

\begin{abstract}
The development of suicide gene therapy with gene products that are directly toxic to cells, such as the A subunit of diphtheria toxin (DT-A), has been hampered by the difficulty of engineering recombinant viruses. DT-A is a strong inhibitor of protein synthesis that acts by ADP-ribosylating elongation factor 2, and a low level of DT-A expression in virus producer cells prevents the production of recombinant virus. We analyzed here the natural resistance of packaging cells to DT-A toxicity, and we report that PG13 and PA317 packaging cell lines are resistant to $\mathrm{H} 21 \mathrm{G}$, a DT-A mutant. PG13 cells produce recombinant $\mathrm{H} 21 \mathrm{G}$ virus that efficiently kills a variety of human tumor cells. Our finding indicates that PG13 packaging cells provide a new potential for the development of DT-A-based suicide gene therapy.
\end{abstract}

Suicide gene therapy has been widely investigated for the treatment of human immunodeficiency virus infection (2), for controlling graft-versus-host disease (31), and also for the treatment of cancer (2). Suicide genes code mainly for enzymes that activate prodrugs into toxic compounds. The most popular genes used in these strategies code for the cytosine deaminase (22) and the herpes simplex virus thymidine kinase (TK) (21). TK transforms the prodrug ganciclovir into a toxic compound; thus, the TK gene is easier to manipulate compared to genes that code for products that are directly toxic to cells such as the gene encoding the A subunit of diphtheria toxin (DT-A). The production of recombinant viruses containing TK or cytosine deaminase are easily achievable, but the generation of viruses containing DT-A has always been a challenge very difficult to fulfill due to the extreme toxicity of DT-A (33). DT is made of two subunits: the A fragment that contains the catalytic activity and the B subunit that binds to receptors present at the surface of the cells (4). DT-A is a strong inhibitor of protein synthesis that catalyzes the ADP-ribosylation of diphtamide, a posttranslationally modified histidine residue present in the elongation factor 2 (EF-2) (4). Use of the DT-A gene for suicide gene therapy would have an advantage over genes such as the TK gene because no prodrug would have to be administered. Indeed, the efficacious prodrug concentration for the TK strategy is not always achievable in vivo, and some cells that contain TK can be resistant to ganciclovir killing (29). Two strategies could be envisaged to overcome the toxicity of DT-A in order to generate recombinant viruses. One approach could rely on controlling DT-A expression during the phase of viral production. The second approach could be to engineer virus producer cells that would be resistant to DT-A toxicity. One way to try to control DT-A toxicity would be at the transcriptional level by using promoters that would be turned off in the virus pro-

* Corresponding author. Mailing address: Le Centre de Recherche en Cancérologie de l'Université Laval, L'Hôtel Dieu de Québec, Centre Hospitalier Universitaire de Québec, 9 rue Mac Mahon, Québec G1R 2J6, Canada. Phone: (418) 525-4444, ext. 5537. Fax: (418) 6915439. E-mail: manuel.caruso@crhdq.ulaval.ca. ducer cells but that could be activated in target cells. Several groups reported a good control of DT-A expression with transcriptional approaches, as demonstrated by a lack of protein synthesis inhibition in transient transfections $(3,10,14,15$, 23-25). However, the toxicity was not completely abolished (3), even with attenuated versions of DT-A (10).

Chinese hamster ovary (CHO-K1) cells that are resistant to DT have been engineered by mutagenesis followed by selection with medium supplemented with DT. Three different groups selected $\mathrm{CHO}-\mathrm{K} 1$ cell lines that contain one or both EF-2 alleles that were mutated, making these cells partially or completely resistant to DT $(6,7,11,12,19,20)$. In theory, it could be possible to engineer packaging cell lines derived from DT-resistant cells or to generate DT-resistant packaging cells from already-existing retrovirus producer cells. Since CHO-K1 cells produce a soluble factor that inhibits retrovirus infection (18), our strategy was to identify or create a DT-resistant cell line from packaging cells currently used in gene therapy.

PG13 and PA317 packaging cells are resistant to the toxicity of H21G. Retroviral plasmids containing DT-A (MFG-DT-A) or a mutant of DT-A (MFG-H21G) were derived from the MFGb2 vector (28). DT-A or $\mathrm{H} 21 \mathrm{G}$, along with a downstream neo resistance $\left(\mathrm{Neo}^{\mathrm{r}}\right)$ gene linked to an internal ribosomal entry site (IRES) were cloned in MFGb2, and they were tested to address the difference in DT sensitivity of several packaging cell lines. H21G contains a glycine substitution in place of histidine at amino acid position 21 (9). It has a reduced enzymatic activity compared to DT-A; however, it is expected to be toxic to cells (9). In order to test the natural DT-A sensitivity of packaging cells, these plasmids and MFG-VZVTK, a nontoxic control plasmid, were transfected by the calcium phosphate procedure into the FLYRD18 (5), GP+envAM12 (13), PA317 (16), and PG13 (17) packaging cell lines. PA317 cells were transfected with $1 \mu \mathrm{g}$, and $3 \mu \mathrm{g}$ of plasmid was used to transfect the other packaging cell lines. On the following day, FLYRD18 cells were selected with $500 \mu \mathrm{g}$ of G418 (GibcoBRL, Rockville, Md.)/ml and other cell lines at $800 \mu \mathrm{g} / \mathrm{ml}$ for a period of 10 days.

Both genes of the bicistronic vectors used in this study are 


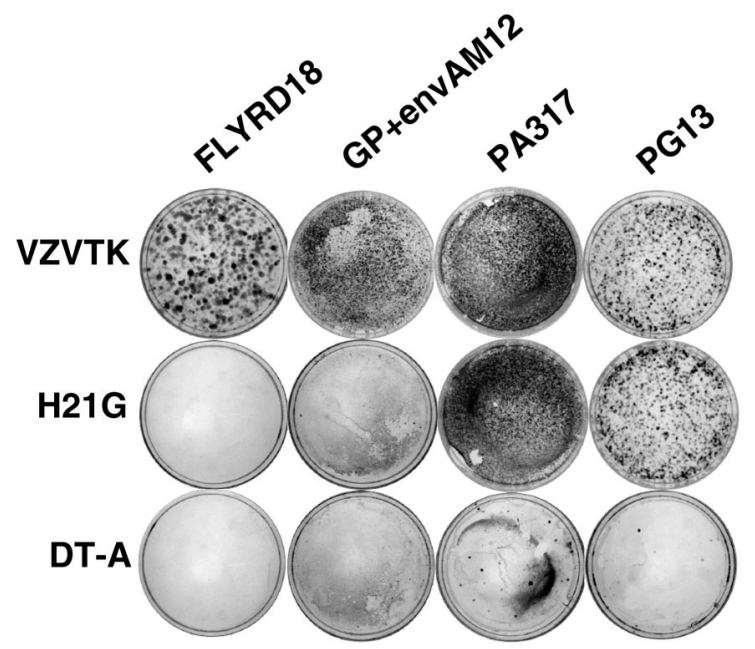

FIG. 1. PG13 and PA317 packaging cell lines are resistant to the toxicity induced by $\mathrm{H} 21 \mathrm{G}$. After calcium phosphate transfection, cells were selected in G418 for 10 days, fixed, and stained with methylene blue. FLYRD18, GP+envAM12, PA317, and PG13 cells were tranfected with the plasmids MFG-VZVTK, MFG-H21G, and MFGDT-A.

under the control of Moloney murine leukemia virus long terminal repeat, with the $\mathrm{Neo}^{\mathrm{r}}$ gene expressed in a cap-independent manner due to its location downstream the IRES. In theory, cells resistant to G418 should express the gene placed upstream the IRES. All cell lines were easily transfected, as shown by the high number of colonies present with the control plasmid (Fig. 1). With the MFG-DT-A plasmid, there were no colonies on the plates with the FLYRD18 and GP+envAM12 cells, and there were only a few colonies with the PA317 and PG13 cells. With MFG-H21G, there were very few colonies on the plates with the FLYRD18 and GP+envAM12 cells, but with the PA317 and PG13 cells the numbers of colonies were similar to those of the control plates (Fig. 1). These results suggested a partial resistance of PG13 and PA317 packaging cell lines to DT-A toxicity, as shown by an absence of toxicity mediated by $\mathrm{H} 21 \mathrm{G}$.

PG13 packaging cells produce retroviruses containing H21G. Supernatants from stable PG13 and PA317 cell lines transfected with $20 \mu \mathrm{g}$ of MFG-H21G plasmid were tested for virus production and virus function. These transfected populations were made up of more than 200 G418-resistant clones for PG13 and PA317 cells and fewer than 10 clones for FLYRD18 and GP+envAM12 cells. The low number of clones with the FLYRD18 and GP+envAM12 cells was due to the toxicity mediated by MFG-H21G on these cells (Fig. 1). CHO-K1 and RE1.22c cell lines (RE1.22c cells have both alleles of EF-2 mutated, which confers resistance to DT) (19) were infected with viral supernatants from the PG13, PA317, FLYRD18, and GP+envAM12 cell lines transfected with MFG-H21G. Cells were seeded in six-well plates at a density of $3 \times 10^{5}$ per well. Four hours later, cells were treated with tunicamycin at $0.4 \mu \mathrm{g} / \mathrm{ml}$ for a period of $20 \mathrm{~h}$; hamster cells become susceptible to retroviral infection after treatment with the glycosylation inhibitor tunicamycin (18). Cells were then infected with $0.1 \mathrm{ml}$ of viral supernatant from PG13 or
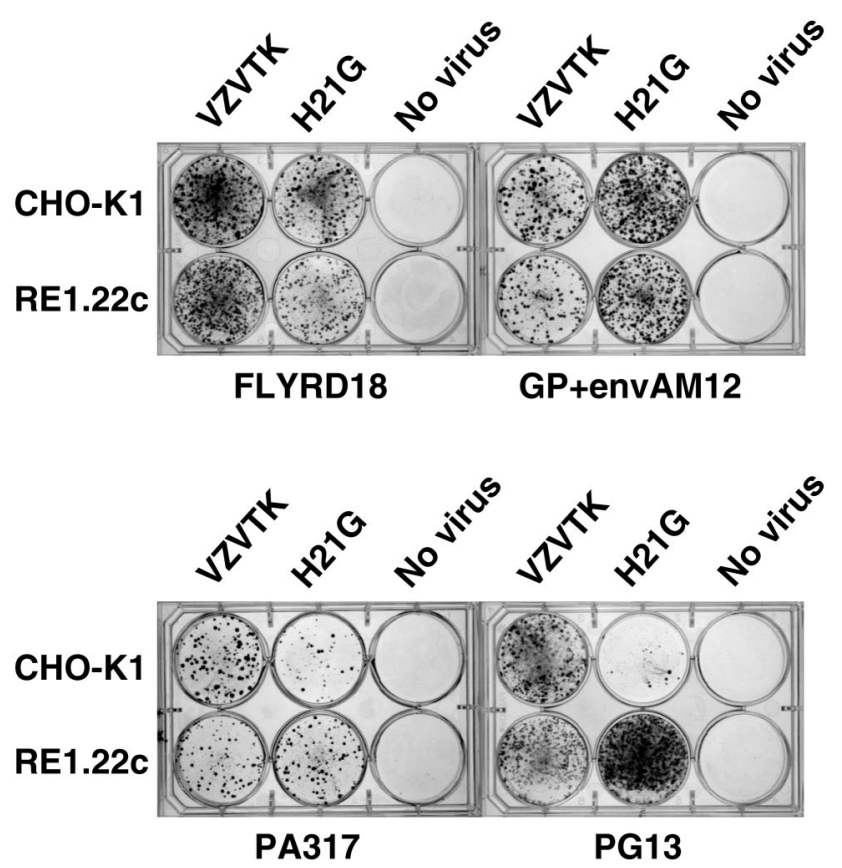

FIG. 2. PG13 and PA317 packaging cells release functional MFG$\mathrm{H} 21 \mathrm{G}$ virus. $\mathrm{CHO}-\mathrm{K} 1$ and RE1.22c cells were infected with viral supernatants, and cells were selected 10 days in G418, followed by fixation and staining. Supernatants from packaging cells transfected with MFG-VZVTK and MFG-H21G were used to infect CHO-K1 cells and RE1.22c cells. Control wells were not infected with virus.

FLYRD18 cells or $0.5 \mathrm{ml}$ of viral supernatant from GP+envAM12 or PA317 cells in the presence of $8 \mu \mathrm{g}$ of Polybrene/ml. Amphotropic virus is poorly infectious on hamster cells despite tunicamycin treatment $(18,30)$; a centrifugation protocol $\left(32^{\circ} \mathrm{C}\right.$ at $1,200 \times g$ for $\left.90 \mathrm{~min}\right)$ was therefore used to increase gene transfer with viruses produced from GP+envAM12 and PA317 cells. Colonies were then selected with $500 \mu \mathrm{g}$ of $\mathrm{G} 418 / \mathrm{ml}$.

The MFG-VZVTK control virus produced from the four packaging cell lines gave rise to numerous G418-resistant colonies in CHO-K1 and RE1.22c cells (Fig. 2). The supernatant produced from PG13 and PA317 cell lines transfected with MFG-H21G gave a high number of colonies that was similar to the result for the control virus with RE1.22c cells, but there were only a few colonies on CHO-K1 cells. With the supernatant derived from FLYRD18 and GP+envAM12 cells transfected with MFG-H21G, similar numbers of colonies were present on CHO-K1 and RE1.22c cells (Fig. 2). This result suggested that the few FLYRD18 and GP+envAM12 clones were producing a virus that could confer G418 resistance but that did not express a functional H21G. Virus titers from isolated PG13 and PA317 clones transfected with MFG-H21G plasmid were measured and compared to MFG-VZVTK and MFG-Neo ${ }^{r}$ titers (Table 1). The MFG-Neo ${ }^{r}$ plasmid was constructed by inserting the $\mathrm{Neo}^{\mathrm{r}}$ gene into the MFGb2 vector. The highest-titer clone derived from PG13 cells producing MFG-H21G virus (Pc4H21G) had a fourfold-lower titer than that of the MFG-Neo ${ }^{\mathrm{r}}$ clone $\left(\mathrm{PcNeo}^{\mathrm{r}}\right)$ with $\mathrm{RE} 1.22 \mathrm{c}$ cells. MFG-Neo ${ }^{r}$ virus had a high titer with HeLa cells, although 
TABLE 1. H21G virus titers

\begin{tabular}{|c|c|c|}
\hline \multirow{2}{*}{$\begin{array}{c}\text { Vector-producing } \\
\text { cell line and virus } \\
\text { type }\end{array}$} & \multicolumn{2}{|c|}{$\begin{array}{l}\text { Titer (no. of G418-resistant colonies/ } \\
\qquad \mathrm{ml})^{a}\end{array}$} \\
\hline & $\mathrm{RE} 1.22 \mathrm{c}$ & $\mathrm{HeLa}$ \\
\hline \multicolumn{3}{|l|}{ PG13 } \\
\hline $\mathrm{Neo}^{\mathrm{r} b}$ & $2.6 \times 10^{5}$ & $8 \times 10^{5}$ \\
\hline $\mathrm{H} 21 \mathrm{G}^{c}$ & $6.8 \times 10^{4}$ & $1.2 \times 10^{2}$ \\
\hline \multicolumn{3}{|l|}{ PA317 } \\
\hline $\mathrm{VZVTK}^{d}$ & $1.8 \times 10^{2}$ & $1.1 \times 10^{3}$ \\
\hline $\mathrm{H} 21 \mathrm{G}^{e}$ & $1.4 \times 10^{2}$ & $<10^{f}$ \\
\hline
\end{tabular}

${ }^{a}$ Titers were measured by infecting cells with limiting dilutions of viral supernatants and counting the G418-resistant colonies. Titers were performed three times with PG13 viruses and twice with PA317 viruses. Values represent the means of these experiments.

${ }^{b}$ Virus produced from a single clone.

${ }^{c}$ Virus produced from clone 4.

${ }^{d}$ Virus produced from a population of clones

${ }^{e}$ Virus produced from a single clone.

${ }^{f}$ No colonies were present with $100 \mu \mathrm{l}$ of virus.

MFG-H21G gave a very low number of colonies due to its toxic effect (Table 1). The best PA317 clone producing MFG-H21G had a low titer with RE1.22c cells, but the titer was in the same range as the one found with a bulk of PA317 cells producing VZVTK virus. As mentioned above, the low titer found with PA317 virus on hamster cells was mainly due to the low infectious property of amphotropic virus, as has been reported by others $(18,30)$. No colonies could be detected with HeLa cells infected with MFG-H21G, although a reasonable titer was measured with MFG-VZVTK (Table 1). These experiments demonstrated that PG13 packaging cells released a functional MFG-H21G virus.

MFG-H21G virus can kill human tumor cells. To test the toxicity of MFG-H21G virus on human tumor cells, $100 \mu \mathrm{l}$ of supernatant produced from Pc4H21G cells was used to infect cancer cells from different origins. After G418 selection (with 400 to $800 \mu \mathrm{g} / \mathrm{ml}$, depending on the cell line), a large number of colonies was present with the control virus MFG-VZVTK, whereas with the MFG-H21G virus only two colonies were detected with HT-1080 cells and none were detected with the other cell lines (Fig. 3). As shown previously (Fig. 2), titers obtained using RE1.22c cells were very similar with both viruses.

The toxicity induced by $\mathrm{H} 21 \mathrm{G}$ expression is also sufficient to kill human tumor cells without G418. The toxicity of MFG$\mathrm{H} 21 \mathrm{G}$ was quantified on several tumor cell lines by the MTT assay as previously described (27). For cell proliferation assay, $3 \times 10^{4}$ cells/well seeded in 24-well plates were infected during two rounds of centrifugation at 8-h intervals under the conditions described above. The following day, cells were trypsinized and a 1:100 cell dilution was distributed in 96-well plates and cultured for 5 days. The proliferation of all human tumor cells was strongly inhibited when they were infected with MFG$\mathrm{H} 21 \mathrm{G}$ compared to cells infected with MFG-Neo ${ }^{\mathrm{r}}$ or uninfected cells (Fig. 4). As expected, the proliferation of RE1.22c cells was not affected by MFG-H21G (Fig. 4A). In this experiment, the efficiency of transduction was measured and evaluated to be $>75 \%$ with the centrifugation protocol (data not shown). A slight inhibition of cell proliferation was observed with HT-1080, SKI-1, and HeLa cells infected with MFG-Neo ${ }^{\mathrm{r}}$.

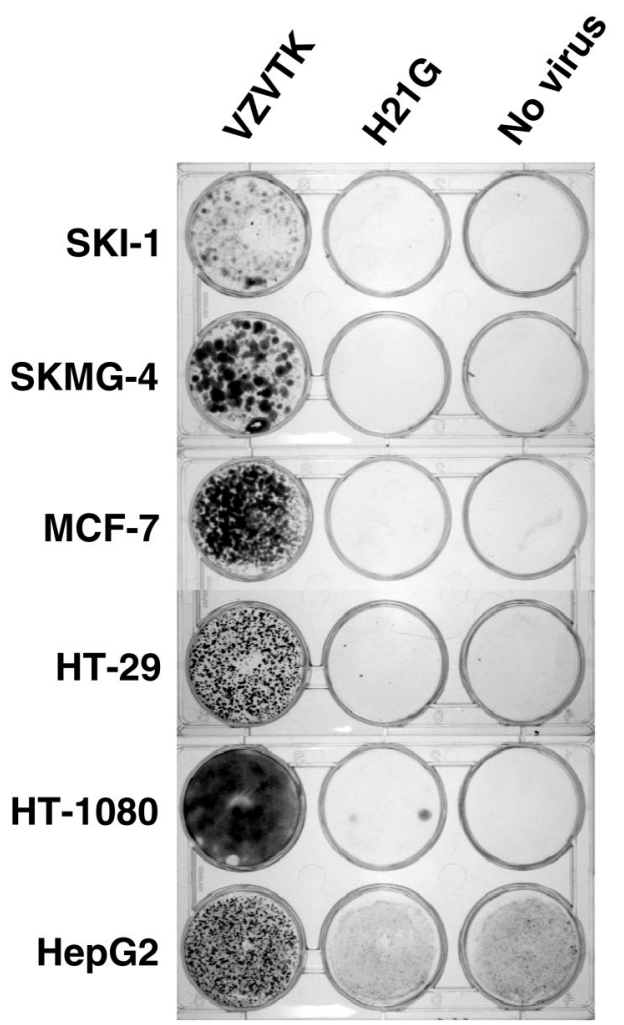

FIG. 3. MFG-H21G virus produced from $\mathrm{Pc} 4 \mathrm{H} 21 \mathrm{G}$ is toxic to tumor cells in a G418 resistance colony assay. MFG-VZVTK viral supernatant, MFG-H21G viral supernatant from Pc4H21G, or medium alone (no virus) was added to the human tumor cell lines SKI-1 (glioblastoma), SKMG-4 (glioblastoma), MCF-7 (breast cancer), HT-29 (colon cancer), HT-1080 (fibrosarcoma), and HepG2 (hepatoma). Fixation and staining were performed 10 to 12 days after G418 selection was started.

The virus, the free envelope (often present in viral supernatants), or other factors released by PG13 cells associated with the centrifugation could be responsible for this toxicity.

Overall, this result indicated that, despite less activity demonstrated by $\mathrm{H} 21 \mathrm{G}$ compared to DT-A, its expression was toxic to human tumor cells.

DT can ADP-ribosylate EF-2 from PG13 and PA317 cells. RE1.22c cells are resistant to DT because both alleles of EF-2 are mutated, and these genetic alterations prevent DT-A from ADP-ribosylating EF-2 (6). A similar mechanism of resistance with PG13 and PA317 cells could be responsible for the production of the recombinant retrovirus MFG-H21G. Therefore, the possibility that EF-2 from PG13 and PA317 cells could not be ADP-ribosylated by DT was investigated in vitro. Cellular extracts of the different packaging cells used in this study, as well as cellular extracts from $\mathrm{CHO}-\mathrm{K} 1$ and RE1.22c cells, were incubated with DT and $\left[{ }^{14} \mathrm{C}\right] \mathrm{NAD}^{+}$. The preparation of cell extracts and the ADP-ribosylation assay of EF-2 were performed according to the protocol described by Kohno et al. (12) with $4 \mu \mathrm{g}$ of DT (Sigma, St. Louis, Mo.).

DT was able to catalyze the ADP-ribosylation of EF-2 from $\mathrm{CHO}-\mathrm{K} 1$ cells and, as expected, ADP-ribosylation could not be detected with the mutated EF-2 from RE1.22c cells (Fig. 5). EF-2 from GP+envAM12 and FLYRD18 cells was ADP-ribo- 
A

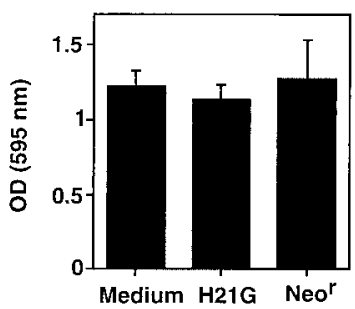

D

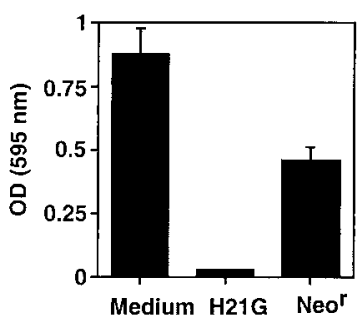

B

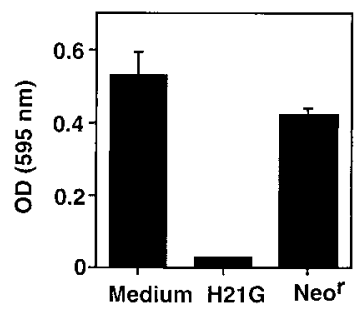

E

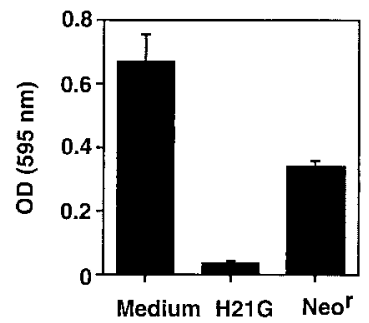

c

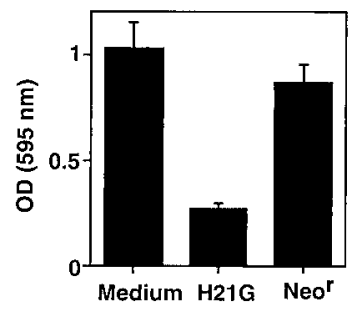

F

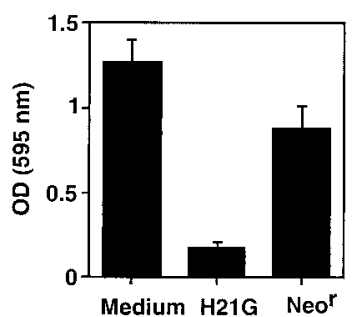

FIG. 4. Inhibition of proliferation of tumor cells with MFG-H21G virus. MFG-Neo ${ }^{\mathrm{r}}$ virus produced from PcNeo ${ }^{\mathrm{r}}$ and MFG-H21G virus released from Pc4H21G or medium were added to RE1.22c (A), SKMG-4 (B), MCF-7 (C), HT-1080 (D), SKI-1 (E), and HeLa (F) cells. At 6 days after infection, cell proliferation was measured by the MTT assay. The data are represented by the optical density measured at $595 \mathrm{~nm}$ and are the average of five values \pm the standard deviation $(\mathrm{SD})$.

sylated by DT as efficiently as from CHO-K1 cells. DT was also able to ADP-ribosylate EF-2 from PG13 and PA317 cells but to a lesser extent from the other cell lines (Fig. 5).

H21G expressed in PG13 cells is a poor inhibitor of protein synthesis. H21G is toxic to cells, presumably by inhibiting protein synthesis. The strength of DT-A and H21G as inhibitors of protein synthesis was compared in HeLa, FLYRD18, and PG13 cells by transient transfections. PG13, FLYRD18, and $\mathrm{HeLa}$ cells were seeded at $3 \times 10^{5}$ cells in 35 -mm dishes. The cells were cotransfected with $2 \mu \mathrm{g}$ of the luciferase reporter plasmid pGL3 (Promega, Madison, Wis.) and $5 \mu \mathrm{g}$ of MFG-DT-A or MFG-H21G or MFG-Neo ${ }^{\mathrm{r}}$ plasmid by using

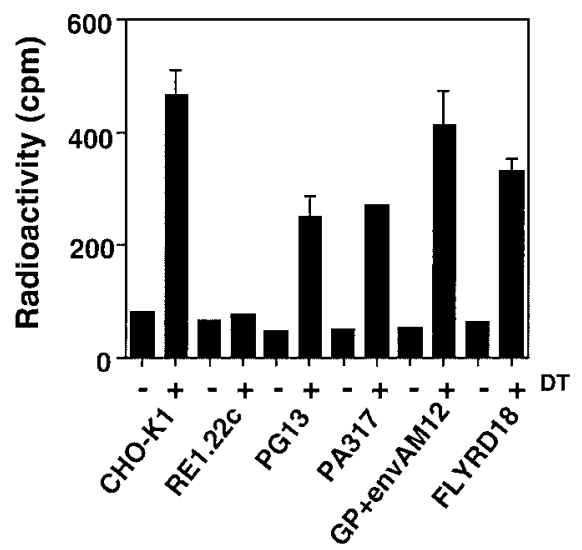

FIG. 5. ADP-ribosylation of EF-2. Cell extracts from CHO-K1, RE1.22c, PG13, PA317, GP+envAM12, and FLYRD18 cells were incubated with DT and $\left[{ }^{14} \mathrm{C}\right] \mathrm{NAD}^{+}$. The reaction mixture was then spotted on a membrane, and the radioactivity associated with EF-2 was determined with a scintillation counter. The values are represented by the average \pm the $\mathrm{SD}$ of an experiment done in triplicate.
Superfect (Qiagen, Valencia, Calif.). Luciferase activity from cell extracts was measured the next day, and the results were adjusted to the protein content of cell lysates determined with the Bio-Rad DC Protein Assay (Bio-Rad, Hercules, Calif.).

In this assay, the coexpression of DT-A with luciferase led to a strong inhibition of reporter gene activity with HeLa and FLYRD18 cells; with PG13 cells, the inhibition was less pronounced (Fig. 6). When MFG-H21G plasmid was cotransfected with the luciferase plasmid, the inhibition of protein synthesis was also very potent with HeLa and FLYRD18 cells. With PG13 cells, however, the luciferase activity was reduced $<2$-fold compared to the control transfected with MFG-Neo ${ }^{\mathrm{r}}$ (Fig. 6). Thus, H21G expression had a weak effect on the level of protein synthesis in PG13 cells.

In this study, we document retrovirus producer cells that

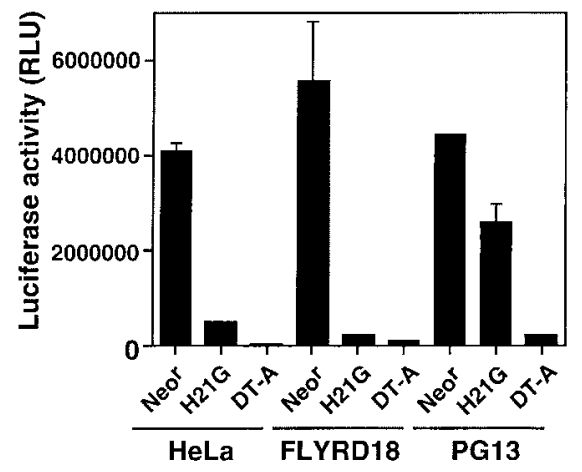

FIG. 6. Inhibition of protein synthesis after transfection with MFGDT-A and MFG-H21G plasmids. HeLa, FLYRD18, and PG13 cells were cotransfected with MFG-Neor ${ }^{\mathrm{r}}$, MFG-H21G, or MFG-DT-A and the luciferase-expressing plasmid pGL3. The luciferase values are represented by the average \pm the $\mathrm{SD}$ of an experiment done in triplicate. 
are partially resistant to DT-A. Our results demonstrate that PG13 and PA317 cells are resistant to H21G toxicity and that PG13 cells produce a recombinant MFG-H21G virus with relatively high titers compared to a nontoxic virus (Table 1). This resistance to $\mathrm{H} 21 \mathrm{G}$ seems to be due to a poor inhibition of protein synthesis by $\mathrm{H} 21 \mathrm{G}$ in PG13 cells (Fig. 6). One possible mechanism to explain this resistance could be that EF-2 is not efficiently ribosylated by H21G in PG13 and PA317 cells. Since both PG13 and PA317 cells are derived from the same cell line NIH $3 \mathrm{~T}_{3} \mathrm{TK}^{-}$, the resistance to $\mathrm{H} 21 \mathrm{G}$ toxicity is probably a feature of the parental cell line.

The expression of DT-A under the control of Moloney murine leukemia virus long terminal repeat was toxic to all packaging cells tested in this study (Fig. 1), but the data suggest that DT did not ADP-ribosylate EF-2 from PG13 and PA317 as efficiently as it did EF-2 from CHO-K1, GP+envAM12, and FLYRD18 cells (Fig. 5). A low level of expression of DT-A in PG13 or PA317 cells would probably not be as harmful as with other packaging cell lines, and it would then be possible to produce retroviruses containing DT-A. PA317 was used to generate DT-A-regulatable vectors for the treatment of human immunodeficiency virus infection (8) and for the treatment of acute myeloid leukemia (32). We suspect that these results showing the production of recombinant retroviruses containing a controllable DT-A are partially due to the spontaneous resistance of PA317 cells to the toxin.

One other study reported the control of DT-A expression in eukaryotic cells: the strategy of regulated recombination (rather than regulated transcription) had allowed the inducible expression of DT-A (1). This could potentially be applied in gene therapy, but the large size of the regulatable DNA cassette used in this approach would limit its application to adenoviral or nonviral vectors; furthermore, background recombination occurs without induction (1). Recently, the generation of a single retrovirus carrying genes coding for a regulatable DT-A and a transcription factor that becomes active upon addition of rapamycin showed a tight control of DT-A toxicity (26). However, the titer was extremely low and the toxicity of DT-A was induced in less than half of the clones transduced by the vector (26).

In conclusion, the present study pinpoints retrovirus packaging cell lines that are partially resistant to DT-A toxicity and shows that it is feasible to produce recombinant retroviruses containing an attenuated version of the DT-A gene highly efficient for suicide gene therapy.

This work was supported by a grant from Canadian Institutes of Health Research (MT-15386). Manuel Caruso is a Research Scholar of the Fonds de la Recherche en Santé du Québec.

We are grateful to Luc Bélanger, Pedro Otavio de Campos-Lima, and Sandra Paik for critical reading of the manuscript. We thank Lloyd Mitchell for the gift of DT-A and H21G genes and Jan Balzarini for providing VZVTK.

\section{REFERENCES}

1. Angrand, P. O., C. P. Woodroofe, F. Buchholz, and A. F. Stewart. 1998 Inducible expression based on regulated recombination: a single vector strategy for stable expression in cultured cells. Nucleic Acids Res. 26:3263-3269.

2. Caruso, M. 1996. Gene therapy against cancer and HIV infection using the gene encoding herpes simplex virus thymidine kinase. Mol. Med. Today 2:212-217.

3. Caruso, M., G. Tsikas, M. Roussel, M. Alizon, and D. Klatzmann. 1992. Can diphtheria toxin be used for gene therapy of human immunodeficiency virus infection? AIDS Res. Hum. Retrovir. 8:1949-1950.

4. Collier, R. J. 1975. Diphtheria toxin: mode of action and structure. Bacteriol. Rev. 39:54-85.

5. Cosset, F. L., Y. Takeuchi, J. L. Battini, R. A. Weiss, and M. K. Collins. 1995 High-titer packaging cells producing recombinant retroviruses resistant to human serum. J. Virol. 69:7430-7436.

6. Foley, B. T., J. M. Moehring, and T. J. Moehring. 1995. Mutations in the elongation factor 2 gene which confer resistance to diphtheria toxin and Pseudomonas exotoxin A. Genetic and biochemical analyses. J. Biol. Chem. 270:23218-23225.

7. Gupta, R. S., and L. Siminovitch. 1978. Diphtheria-toxin-resistant mutants of $\mathrm{CHO}$ cells affected in protein synthesis: a novel phenotype. Somat. Cell Genet. 4:553-571.

8. Harrison, G. S., C. J. Long, T. J. Curiel, F. Maxwell, and I. H. Maxwell. 1992. Inhibition of human immunodeficiency virus-1 production resulting from transduction with a retrovirus containing an HIV-regulated diphtheria toxin A chain gene. Hum. Gene Ther. 3:461-469.

9. Johnson, V. G., and P. J. Nicholls. 1994. Histidine 21 does not play a major role in diphtheria toxin catalysis. J. Biol. Chem. 269:4349-4354.

10. Keyvani, K., I. Baur, and W. Paulus. 1999. Tetracycline-controlled expression but not toxicity of an attenuated diphtheria toxin mutant. Life Sci. 64:1719-1724.

11. Kohno, K., and T. Uchida. 1987. Highly frequent single amino acid substitution in mammalian elongation factor 2 (EF-2) results in expression of resistance to EF-2-ADP-ribosylating toxins. J. Biol. Chem. 262: 12298-12305.

12. Kohno, K., T. Uchida, E. Mekada, and Y. Okada. 1985. Characterization of diphtheria-toxin-resistant mutants lacking receptor function or containing nonribosylatable elongation factor 2. Somat. Cell Mol. Genet. 11:421-431.

13. Markowitz, D., S. Goff, and A. Bank. 1988. Construction and use of a safe and efficient amphotropic packaging cell line. Virology 167:400-406.

14. Massuda, E. S., E. J. Dunphy, R. A. Redman, J. J. Schreiber, L. E. Nauta, F. G. Barr, I. H. Maxwell, and T. P. Cripe. 1997. Regulated expression of the diphtheria toxin A chain by a tumor-specific chimeric transcription factor results in selective toxicity for alveolar rhabdomyosarcoma cells. Proc. Natl. Acad. Sci. USA 94:14701-14706.

15. Maxwell, I. H., F. Maxwell, and L. M. Glode. 1986. Regulated expression of a diphtheria toxin A-chain gene transfected into human cells: possible strategy for inducing cancer cell suicide. Cancer Res. 46:4660-4664.

16. Miller, A. D., and C. Buttimore. 1986. Redesign of retrovirus packaging cell lines to avoid recombination leading to helper virus production. Mol. Cell. Biol. 6:2895-2902.

17. Miller, A. D., J. V. Garcia, N. von Suhr, C. M. Lynch, C. Wilson, and M. V. Eiden. 1991. Construction and properties of retrovirus packaging cells based on gibbon ape leukemia virus. J. Virol. 65:2220-2224.

18. Miller, D. G., and A. D. Miller. 1992. Tunicamycin treatment of CHO cells abrogates multiple blocks to retrovirus infection, one of which is due to a secreted inhibitor. J. Virol. 66:78-84.

19. Moehring, J. M., and T. J. Moehring. 1979. Characterization of the diphtheria toxin-resistance system in Chinese hamster ovary cells. Somat. Cell Genet. 5:453-468.

20. Moehring, T. J., and J. M. Moehring. 1977. Selection and characterization of cells resistant to diphtheria toxin and pseudomonas exotoxin A: presumptive translational mutants. Cell 11:447-454.

21. Moolten, F. L. 1986. Tumor chemosensitivity conferred by inserted herpes thymidine kinase genes: paradigm for a prospective cancer control strategy. Cancer Res. 46:5276-5281.

22. Mullen, C. A., M. Kilstrup, and R. M. Blaese. 1992. Transfer of the bacterial gene for cytosine deaminase to mammalian cells confers lethal sensitivity to 5-fluorocytosine: a negative selection system. Proc. Natl. Acad. Sci. USA 89:33-37.

23. Murayama, Y., T. Tadakuma, M. Kunitomi, K. Kumai, K. Tsutsui, T. Yasuda, and M. Kitajima. 1999. Cell-specific expression of the diphtheria toxin A-chain coding sequence under the control of the upstream region of the human alpha-fetoprotein gene. J. Surg. Oncol. 70:145-149.

24. Pang, S. 2000. Targeting and eradicating cancer cells by a prostate-specific vector carrying the diphtheria toxin A gene. Cancer Gene Ther. 7:991-996.

25. Paulus, W., I. Baur, D. M. Oberer, X. O. Breakefield, and S. A. Reeves. 1997. Regulated expression of the diphtheria toxin A gene in human glioma cells using prokaryotic transcriptional control elements. J. Neurosurg. 87:89-95.

26. Pollock, R., R. Issner, K. Zoller, S. Natesan, V. M. Rivera, and T. Clackson. 2000. Delivery of a stringent dimerizer-regulated gene expression system in a single retroviral vector. Proc. Natl. Acad. Sci. USA 97:13221-13226.

27. Qiao, J., E. M. Black, and M. Caruso. 2000. Enhanced ganciclovir killing and bystander effect of human tumor cells transduced with a retroviral vector carrying a herpes simplex virus thymidine kinase gene mutant. Hum. Gene Ther. 11:1569-1576.

28. Riviere, I., K. Brose, and R. C. Mulligan. 1995. Effects of retroviral vector design on expression of human adenosine deaminase in murine bone marrow 
transplant recipients engrafted with genetically modified cells. Proc. Natl. Acad. Sci. USA 92:6733-6737.

29. Sturtz, F. G., K. Waddell, J. Shulok, X. Chen, M. Caruso, M. Sanson, H. R. Snodgrass, and D. Platika. 1997. Variable efficiency of the thymidine kinase/ ganciclovir system in human glioblastoma cell lines: implications for gene therapy. Hum. Gene Ther. 8:1945-1953.

30. Tailor, C. S., A. Nouri, and D. Kabat. 2000. Cellular and species resistance to murine amphotropic, gibbon ape, and feline subgroup $\mathrm{C}$ leukemia viruses is strongly influenced by receptor expression levels and by receptor masking mechanisms. J. Virol. 74:9797-9801.
31. Tiberghien, P. 2001. Use of suicide gene-expressing donor T cells to control alloreactivity after haematopoietic stem cell transplantation. J. Intern. Med. 249:369-377.

32. Vallera, D. A., N. Jin, J. M. Baldrica, A. Panoskaltsis-Mortari, S. Y. Chen, and B. R. Blazar. 2000. Retroviral immunotoxin gene therapy of acute myelogenous leukemia in mice using cytotoxic $\mathrm{T}$ cells transduced with an interleukin 4/diphtheria toxin gene. Cancer Res. 60:976-984.

33. Yamaizumi, M., E. Mekada, T. Uchida, and Y. Okada. 1978. One molecule of diphtheria toxin fragment A introduced into a cell can kill the cell. Cell 15:245-250. 